\title{
The patterns of myoelectrical activity and reaction for teat stimulation recorded in highly productive dairy cows' udders
}

\author{
Albert Czerski ${ }^{1}$, Milan Vasil ${ }^{2}$, Juraj Elečko ${ }^{2}$, Zuzana Farkašová2 ${ }^{2}$, František Zigo², Wojciech \\ Zawadzki $^{1}$, Przemysław Dudko ${ }^{3}$, Jan Gnus ${ }^{4}$, Maciej Janeczek ${ }^{1}$, Aleksander Chószcz ${ }^{1}$ \\ ${ }^{1}$ University of Environmental and Life Sciences, Department of Animal Physiology and Biostructure, Institute \\ of Animal Physiology, Wroclaw, Poland \\ ${ }^{2}$ University of Veterinary Medicine and Pharmacy in Košice, Department of Nutrition, Dietetics and Animal \\ Breeding, Institute of Animal Breeding, Slovak Republic \\ ${ }^{3}$ Poznań University of Life Sciences, Department of Veterinary, Poland \\ ${ }^{4}$ Provincial Specialized Hospital, General and Vascular Surgery Ward, Research and Development Center \\ in Wroclaw, Poland
}

Received March 5, 2013

Accepted June 19, 2013

\begin{abstract}
The aim of the study was to evaluate electrical properties of the mammary gland of dairy cow during manual and mechanical milking and to adapt the electrographic method for analysis of udder physiology. Udder myoelectrical activity was measured on 10 healthy highly productive dairy cows of Slovak Pied cattle breed. The electrical activity of four quarters of the udder was recorded simultaneously using four bipolar electrodes. The udder was stimulated by delicate twofinger massage, manual milking and mechanical milking. During the experiment the duration of the reaction for stimulation and the amplitude of spike dischargers were listed. The udder stimulation through palpational massage of the teat end, manual and mechanical milking caused immediate reaction. The udder responded to stimulation with an increase in myoelectrical activity: increase in discharge frequency to $2.33 \pm 0.6$ per min and an increase in discharge amplitude with the average of $457 \pm 147 \mu \mathrm{V}$. The average count of spike discharges was $3.86 \pm 0.97$, the average duration of the action potential was $8.12 \pm 1.68 \mathrm{~s}$ and the average myoelectrical index was $31 \pm 4 \%$. Manual milking caused the highest increase in the udder myoelectrical activity. Evaluation of the mammary gland myoelectrical activity may provide an alternative method to study milk ejection disorders and to diagnose mastitis.
\end{abstract}

Myoelectrical activity, udder health, two-finger massage stimulation, mechanical milking

The electrical activity is an attribute of every living cell. Thanks to the difference in electric potential between the inside of the cell and the outside membrane, the cell has the ability to response to a stimulus. The recording of the udder myoelectrical activity may be an alternative method to study the function of the gland. The method could be used in the diagnosis of milk ejection disorders and other diseases of the mammary gland. The myoelectrical activity analysis is an advanced examination method for indirect tracking of the muscle contractility through reception of action potentials using implanted electrodes. The myoelectrical activity has a direct impact on the tissue contraction. It is a minimally invasive method, so the information obtained during the examination is a reflection of physiological process occurring in the organs.

The aim of the study was to evaluate electrical properties of the mammary gland of dairy cow during manual and mechanical milking and to adapt the electrographic method to the analysis of udder physiology.

\section{Materials and Methods}

Animals and udder examination

Udder myoelectrical activity was measured on 10 highly productive dairy cows of Slovak Pied cattle breed. Before the recording, a sample of milk from each udder's quarter was collected in a sterile way for examination to rule out bacterial infection and inflammation. Only animals qualified as healthy in the milk test were used for the study.

Address for correspondence:

PhD. Albert Czerski

Department of Animal Physiology and Biostructure

C.K. Norwida 31, 50-375 Wroclaw

Phone: +48691521834

E-mail: alb5@tlen.pl

http://actavet.vfu.cz/ 
Clinical changes in the udder were diagnosed by the presence of observable signs of inflammation in the infected quarter, such as swelling, heat, pain or redness, and by the presence of clots and flakes in the milk, or by its abnormal colour or consistency. California mastitis test was performed using equal volumes of milk and alkylaryl-sulphate and was evaluated as: 1) negative (-), not infected, healthy quarter, no thickening of the mixture; 2) trace $( \pm)$, possible infection, slight thickening of the mixture; 3 ) weak positive $(+)$, infected, distinct thickening of the mixture but no tendency to form a gel.

\section{Milk analysis, somatic cell count and pathogen detection}

Quarter milk samples for microbiological examination were collected before milking from each cow. After drawing and evaluation of the first 6 squirts of milk, the teat ends were disinfected with cotton wool dipped in $70 \%$ ethyl-alcohol. Milk was then collected aseptically from teats directly into sterile $10 \mathrm{ml}$ tubes, holding the tubes at an angle of approximately $45^{\circ}$. The samples were kept at $4-8{ }^{\circ} \mathrm{C}$ during transportation to the laboratory.

Quarter milk samples were collected by hand-stripping after CMT (California Mastitis Test) and sample collecting for microbiological examination. Milk was collected from every quarter into a $25 \mathrm{ml}$ tube with stabilized reagent (potassium dichromate at a concentration of $1 \mathrm{mg} / 1 \mathrm{ml}$ ). After shuffling, samples were transported at the temperature of $1-10^{\circ} \mathrm{C}$ to the laboratory and examined within the next $24 \mathrm{~h}$. Somatic cell count in quarter milk samples was detected according to STN EN IS/ 13 366-3: 2000 by Fossomatic 5000 (FOSS Electric, Hølstebro, Denmark).

Milk samples $(0.05 \mathrm{ml})$ were inoculated onto blood agar (Oxoid, UK) and cultivated at $37{ }^{\circ} \mathrm{C}$ for $24 \mathrm{~h}$. Only cows with negative cultivation findings were selected for the experiment.

\section{Experimental procedure}

Animals used for the study were between days 40 and 90 of lactation and were considered healthy. An animal was considered healthy if there were no clinical changes associated to mastitis, there were no lesions in the udder and CMT result was negative - there were no bacteria and the somatic cell count was under 300 thousand per millilitre in the collected material.

Recording of udder myoelectrical activity was conducted using PowerLab/800 (ADInstruments New Zealand) connected to a PC computer. The Chart v.4.1 (ADInstruments) software was used to write, read and analyse the data. In each of the three channels, filters were set as follows: high cut-off filter to $35 \mathrm{~Hz}$ and low cut-off filter to $0.3 \mathrm{~Hz}$ (Haluska et al. 1987; Troedsson et al. 1993; Janszen et al. 1993; Czerski et al. 2012). The signal was enhanced with BioAmp (ADInstruments, Melbourne, Australia). The sampling rate was set to 40 samples per second. The myoelectrical activity was registered using bipolar electrodes. Electrodes used for ECG (Bio LeadLok B, catalogue number: R-LFO-500) were adapted for the study. One electrode was placed at the udder base; the other electrode was placed right at the base of a teat. The electrical activity of four quarters of the udder was recorded simultaneously using four bipolar electrodes. The electrodes were covered with electrocardiography (ECG) gel to provide better contact of the electrodes and the tissue. To prevent the electrodes from falling off, they were additionally taped using woven patch. A 15-min udder myoelectrical activity recording was conducted. Subsequently, the udder was stimulated in order to verify the reaction. The stimulation was carried out in two ways. Primarily, the udder was stimulated by delicate two-finger massage of the teat performed so as to prevent milk flow. The experiment was repeated $3 \times$ on each animal with the stimulation of each quarter as with the simultaneous stimulation of both quarters of one half of the udder. Afterwards, manual milking separately of each quarter as simultaneously of both quarters of one half of the udder was conducted. Mechanical milking was also done. During the experiment, the duration of the reaction to stimulation and the amplitude of spike dischargers were recorded.

\section{Data analysis and statistic}

Obtained electromammograms were analysed off-line using Chart software v 4.1 (ADInstruments) working under Windows 98 OS. The value of myoelectrical index (MI) (Krishnamurti et al. 1982) and the number of spike potential groups per min (Harding et al. 1982; Massmann et al. 1991; Troedsson et al. 1993) were calculated. Moreover, the mean duration of spike potential group, the mean amplitude of spike discharge and the mean number of spike discharges in spike potential group were calculated to describe the patterns of udder myoelectrical activity.

The results were shown as mean values \pm standard deviation $(\bar{x} \pm \mathrm{SD}, P \leq 0.005)$.

$M I=\frac{\sum_{i}^{N} d i}{3600} \cdot 100 \quad$ (control formula)

$\sum_{i}^{N} d i=$ the sum of the durations of spike burst during one hour of recording time 


\section{Results}

The results of the experiment showed that the cow's mammary gland during lactation had myoelectrical activity characterized by the occurrence of spike potential groups with a frequency of $2.33 \pm 0.6 / \mathrm{min}$. The mean duration of action potential group was $8.12 \pm 1.68$ $\mathrm{s}$, the mean amplitude of discharge was $457 \pm 147 \mu \mathrm{V}$, whereas the mean count of spike discharge in the group was $3.86 \pm 0.97$. The myoelectrical index was $31 \pm 4 \%$. There were no significant differences $(P \leq 0.005)$ in myoelectrical activity between the four quarters of the udder. Fig. 1 presents an exemplary recording of udder myoelectrical activity showing registered patterns.

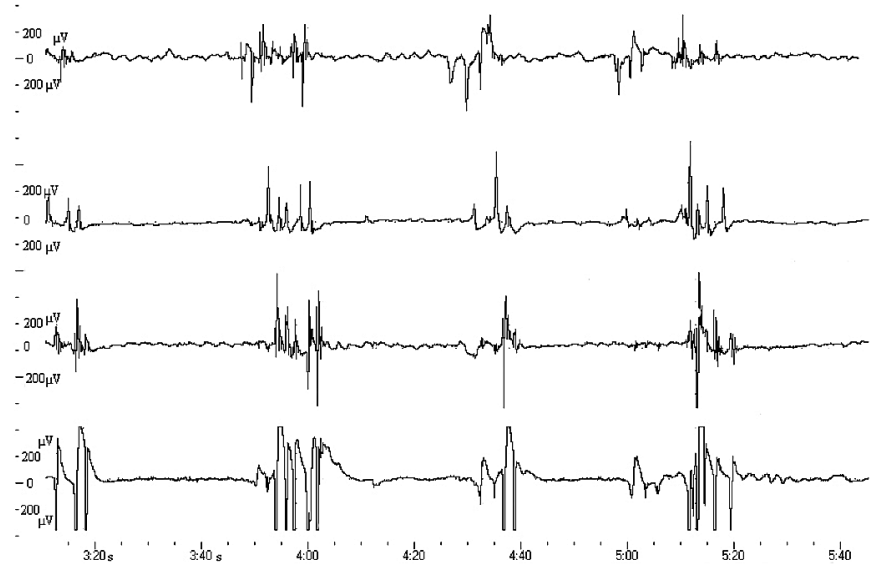

Fig. 1. Recording of spontaneous myoelectrical activity of the cow's mammary gland.

From the top: right front, left front, right back and left back quarter of the udder. The discharge amplitude $(\mu \mathrm{V})$ and time (min) is indicated in the recording.

Udder stimulation by palpational massage of the teat's end caused immediate reaction and increase in myoelectrical activity during stimulation. The reaction time for stimulation averaged $4.68 \pm 1.43 \mathrm{~s}$. During the massage, spike discharges appeared in a continuous way and ceased 5-6 s after the stimulation ended. The average amplitude of registered discharges was $453 \pm 167 \mu \mathrm{V}$. There were no significant differences $(P \leq 0.005)$ in registered myoelectrical activity during teat stimulation in four quarters of the udder. During stimulation the myoelectrical index value increased by $100 \%$. Fig. 2 shows an exemplary recording of the changes in udder myoelectrical activity during teat stimulation.

The udder stimulation during manual milking also caused a reaction manifested by an increase in myoelectrical activity. The average reaction time for stimulation was $3.53 \pm 1.62$ s. The spike discharges appeared continuously during milking and ceased 5-6 s after end of milking. The mean amplitude of registered spike discharges was $673 \pm 186 \mu \mathrm{V}$. There were no significant differences in registered myoelectrical activity during stimulation in the four quarters of the udder. During manual milking, the myoelectrical index value increased to $100 \%$. Fig. 3 shows an exemplary recording of the changes in udder myoelectrical activity during manual milking.

A strong increase in udder myoelectrical activity was also observed during mechanical milking. The spike discharges were present continuously. The average reaction time was 


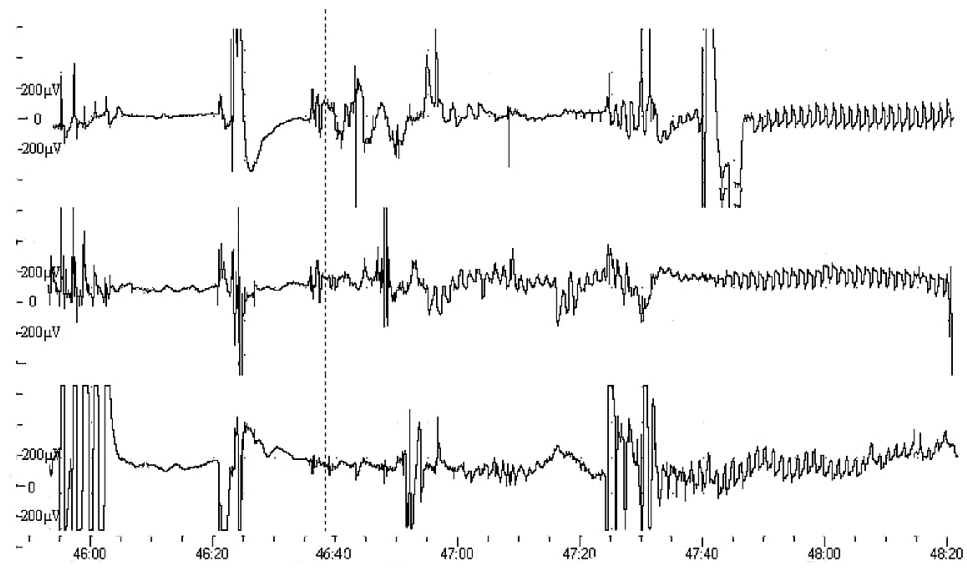

Fig 2. Recording of udder myoelectrical activity response to teat stimulation.

The moment of stimulation is indicated with a dashed line. The high-amplitude continuous spike potentials appear after the stimulation. The discharge amplitude $(\mu \mathrm{V})$ and the time $(\mathrm{min})$ is indicated in the recording.

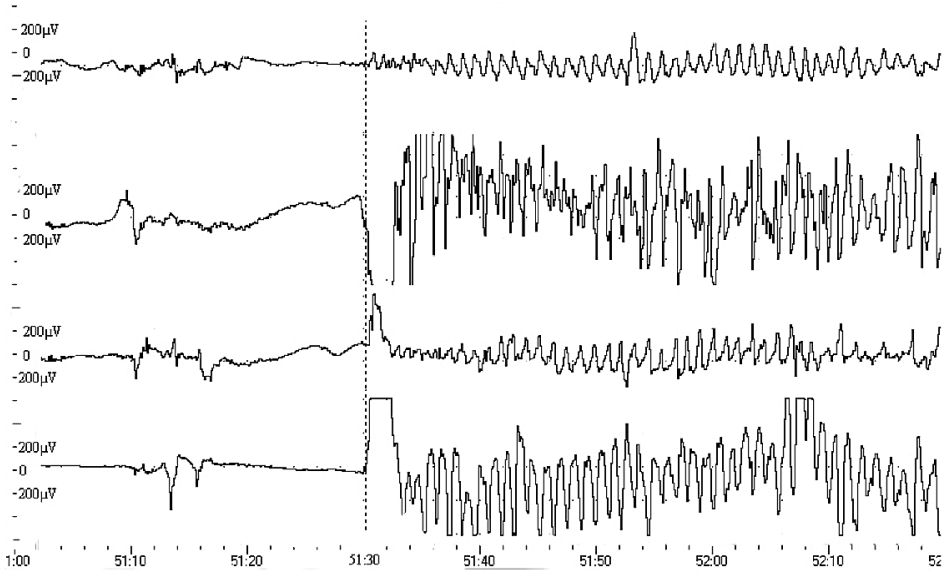

Fig 3. Recording of udder myoelectrical activity after stimulation by manual milking.

Left quarters (chart $2^{\text {nd }}$ and $4^{\text {th }}$ from the top) are stimulated. The moment of stimulation is indicated with a dashed line. The discharge amplitude $(\mu \mathrm{V})$ and the time $(\mathrm{min})$ is indicated on the recording.

$35 \pm 7 \mathrm{~s}$ and the average amplitude of a discharge was $459 \pm 149 \mu \mathrm{V}$. During mechanical milking, the myoelectrical index value increased to $100 \%$. Fig. 4 shows an exemplary recording of udder myoelectrical activity during mechanical milking.

When comparing myoelectrical reactions during teat stimulation, manual milking, and mechanical milking, it is noticeable that manual milking evokes considerably higher increase in myoelectrical activity than teat stimulation or mechanical milking. The average reaction time during manual milking was $24.57 \%$ shorter (this is about $1.15 \pm 0.4 \mathrm{~s}$; $P \leq 0.005)$ than during teat stimulation and almost $10 \times(31.47 \pm 5 \mathrm{~s} ; P \leq 0.005)$ shorter than 


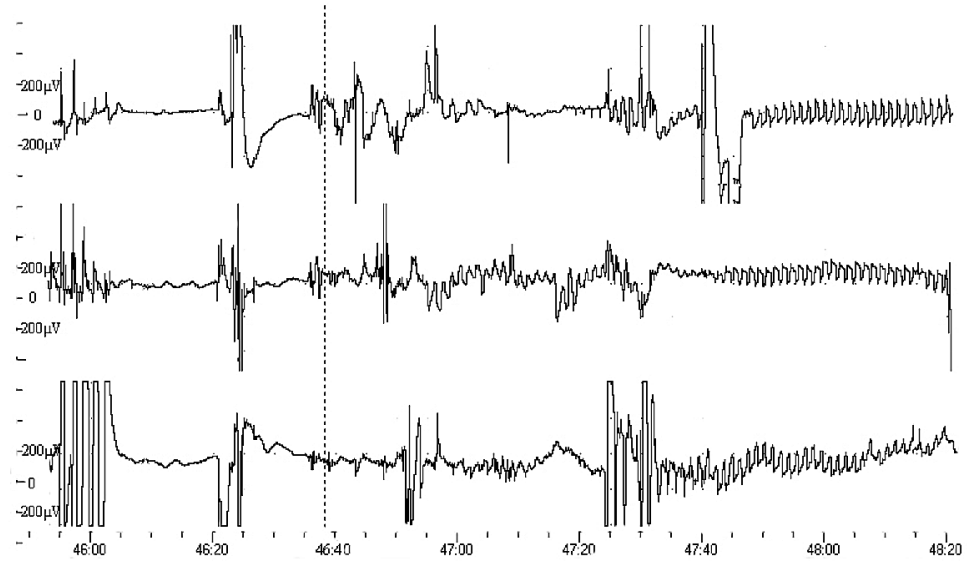

Fig 4. Recording of udder myoelectrical activity after stimulation by mechanical milking.

The milking machine attachment time is indicated with a dashed line. The increase in myoelectrical activity as a response for stimulation can be seen. The continuous spike potentials appear. The discharge amplitude $(\mu \mathrm{V})$ and the time ( $\mathrm{min})$ is indicated in the recording.

during mechanical milking. The average discharge amplitude in manual milking was also $45.35 \%$ higher (this is about $220 \pm 78 \mu \mathrm{V} ; P \leq 0.005$ ) than in teat stimulation and $46.62 \%$ higher (this is about $214 \pm 89 \mu \mathrm{V} ; P \leq 0.005$ ) than in mechanical milking. The change in myoelectrical index values is not a good indicator in the case of describable comparisons.

When comparing teat stimulation and mechanical milking, there is a significant difference $(P \leq 0.005)$ in reaction time, although there is no significant difference in the mean spike discharge amplitude.

\section{Discussion}

The glandular cells inside the mammary gland show electrical activity. It was proven that mice glandular cells isolated from the nipples and multiplied in vitro showed a spontaneous potential oscillation with an amplitude of 5-20 mV and a frequency of 10 per s (Enomoto et al. 1986). Larger groups of cells, which form tissues, apart from the ability to generate bio-signals, show also diverse resistance currents. Differences in the tissue resistance (between blood, muscles, fat and glandular tissue) are used in diagnostic tests (Karpov et al. 1997). The mammary gland is a complex of tubuloalveolar glands surrounded by adipose tissue. The epithelial cells of the nipple are electrically connected to each other. There is a free flow of small molecules such as nucleotides and ions (Shen et al. 1976; Czerski et al. 2005). The flow is possible thanks to the presence of ion-metabolic connection between the cells (gap junction), which were confirmed by electron microscopy (Pitelka et al. 1973; Peracchia and Dulhunky 1976). As shown in many studies, epithelial glandular cells forming the mammary gland do not show action potentials, which also applies to most other epithelial cells (Loewenstein and Penn 1967; Adams et al. 1982). Hormonal stimulation (with EGF-epithelium growth factor or insulin) of those cells, as in mice glandular epithelial cells, causes a spontaneous hyperpolarization, which results in the presence of potentials that can be recorded (Enomoto et al. 1986). It is possible that the reaction is caused by activation of calcium-activated potassium channels (Williams 
1981) or that the hyperpolarizing potential originates from the activation of the sodiumpotassium pump (Enomoto et al. 1986).

The recognition of the udder activity patterns will allow the diagnosis of mastitis based on disturbances found in udder myoelectrical activity or based on the response to stimulation. The results of our study showed the myoelectrical activity of the udder glandular tissue as a presence of groups of spike potentials. There were no significant differences in the myoelectrical activity in different quarters of the udder $(P \leq 0.005)$. There are not many similar reports. Studies carried out on a group of goats showed a spontaneous myoelectrical activity of the udder glandular tissue; the recording was obtained from the surface of the skin (Galantsev et al. 1994). The biopotentials occurred in certain patterns and the authors showed the glandular tissue reaction to milking and electrical and hormonal stimulation (Galantsev et al. 1994). The registered electrical activity is a sum of electrical phenomena occurring between the electrodes. The udder building tissue resistance (adipose tissue, connective tissue and skin) affects the recording and should also be taken into consideration during the study. The frequency and amplitude of groups of spike potentials exclude the possibility of their origin outside the udder tissue. A time correlation can be seen in the emergence of spike potential groups between the quarters of the udder. Although the correlation can be noticed, there are parts of the recording where it is not so clearly visible. The recorded spike potential groups can come from membrane potential oscillation occurring in glandular epithelial cells in response to hormones. They can also originate from the muscle tissue forming the mammary gland. The smooth muscle surrounds the lactiferous alveoli. Muscle contraction causes the milk movement to the lactiferous sinuses. The muscle tissue has the ability to generate spontaneous action potentials thanks to the presence of pacemaker cells. The presence of autonomic nervous system in the udder tissue should also be taken into consideration. The nerve endings release neurotransmitters that cause depolarization in the target cell. Thus, the genesis of registered spike potentials may vary and requires further examination.

Our study showed the udder response to stimulation as an increase in myoelectrical activity. The change in registered patterns of electrical activity was observed both after stimulating the teat and during manual and mechanical milking. Right after the stimulation, spike potentials occurred continuously. The reaction took place as a response to stimulation of the mechanoreceptors localised in the teat. The massage of the teat and the manual and mechanical milking causes similar reaction as in a nursing cow. Calf sucking the udder causes the reflex of lactation as a response to secretion of oxytocin by neurons in hypothalamus. The response is immediate and consists of an emergence of continuous spike potentials in the stimulated quarter. The reaction in non-stimulated quarters is quite different; the increase in their myoelectrical activity is not so escalated. It shows that oxytocin is not the most important factor in stimulating the myoelectrical activity of the udder; since it is delivered with blood, it should stimulate all quarters of the udder in a similar way. On the contrary, the nervous system plays a superior role. Stimulation of teat mechanoreceptors causes an increase in myoelectrical activity in the stimulated udder quarter as a reflex response. Emerging spike potentials are generated in muscle tissue, which undergoes contraction and causes the milk flow to the lactiferous sinus, making milking possible.

In the following stage of the study, the patterns of and reaction to udder stimulation in animals with evidence of mastitis will be developed. It is possible that differences in the myoelectrical activity and in response to stimulation will allow developing a new, easy and fast diagnostic method for this common disease. 


\section{References}

Adams PR, Constanti A, Brown DA, Clark RB 1982: Intracellular $\mathrm{Ca}^{2+}$ ativates a fast voltage-sensitive $\mathrm{K}^{+}$current in vertebrate sympathetic neurones. Nature 296: 746-749

Czerski A, Gnus J, Hauzer W, Ratajczak K, Zawadzki W, Witkiewicz W, Ferenc S, Rusiecka A, Janeczek M 2012: Myoelectric activity of the muscular layer of the abdominal aorta in pigs in vivo. Aca Vet Brno 81: 281-286

Czerski A, Zawadzki W, Zawadzki M, Czerska Z 2005: Influence of dopamine on rat uterine motylicy in vitro. Acta Vet Brno 74: 9-15

Enomoto K, Cossu MF, Edwards C, Oka T 1986: Induction of distinct types of spontaneous electrical activities in mammary epithelial cells by epidermal growth factor and insulin. Proc Natl Acad Sci USA 83: 4754-4758

Galantsev VP, Guliaeva EP, Kuzmin DA, Balakina GB, Popov SM, Uzbekov VV, Shereshkov VI. 1994: Bioelectrical reactions on the surface of the mamma in the goat. Fyziol Zh Im I M Sechenova 80: 132-137

Karpov A, Trokhanova O, Cherepenin V, Korjenevsky A 1997: Electrical impedance anatomy of the mammary gland. Bull Russ Acad Med Sci 4: 52-56

Loewenstein WR, Penn RD 1967: Intercellular communication and tissue growt: II. tissue regeneration. J Cell Biol 33: 235-242

Peracchia C, Dulhunty AF 1976: Low resistance junctions in crayfish. Structural changes with functional uncoupling. J Cell Biol 70: 419-439

Pitelka DR, Hamamoto ST, Duafala JG, Nemanic MK 1973: Cell contacts in the mouse mammary gland: I. normal gland in postnatal development and the secretory cycle. J Cell Biol 56: 797-818

Shen SS, Hamamoto S T, Pitelka D R 1976: Electrophysiological study of coupling between cultured cells of the mouse mammary gland in five distinct physiological states. J Membr Biol 29: 373-382

Williams JA 1981: Electrical correlates of secretion in endocrine and exocrine cells. Fed Proc 40: 128-134 